\title{
Exploration on the English Teaching Reform of Universities under the Micro Age Background
}

\author{
Xiang Yang \\ Baoshan College of Traditional Chinese Medicine, Baoshan Yunnan, 678000, China
}

Keyword: Micro Age, University English, Teaching reform.

\begin{abstract}
With the emerging of Internet Age, digital technology develops popularly, among which, Microblog and Wechat become main communication methods, meanwhile, the development of Micro Age also provide convenient conditions for English teaching. Therefore, changing traditional English teaching form is not only need for age development but also can improve English teaching level on a certain extent. This paper makes a brief introduction for Micro Age and analyzes challenges faced by current university English teaching and their influences and use relevant strategies to improve the English teaching level.
\end{abstract}

\section{Introduction}

China's science and technology level is improving continue, Internet technology is main method for current social progress and living standard improvement. Among which, Microblog and Wechat have become main media for current news transmission. The independence, language and culture of this kind of transmission influenced people's studying and work. Therefore, China's teaching form has developed with Micro Age development.

\section{Overview of Micro Age}

\section{Definition}

Since the emerging of Micro Age, people's communication way, social culture transmission, news transmission and people's living way have changed a lot, which realized modernization of current development. But the definition of Micro Age are different on different forms. Firstly, divide according to transmission property, it is a new emerging transmission media, mainly based on information technology and digital technology to realize words, pictures and videos to realize fast interact transmission. Secondly, divide according to accept angle, Micro Age is a kind of fast age with development of micro product and micro users, can provide a big development power. Thirdly, divide according to industrial base, Microblog is main software for micro product, it not only promote the quickness of information transmission but also convenient for people scanning information. Besides, the Microblog can transfer word, pictures and video information only with cellphone or computer. Fourthly, divide according to main content, under the Micro Age background, mainly include Wechat, Microblog, Microfilm and other forms.

\section{Features}

Micro Age is a new transmission media, compared with traditional medias, it can provide people with new development view. Its main features are:

Transmission in a popular style. With the continue development of science and technology, many digital products realized intelligence and automation and promoted the multiple-direction of 
transmission internet. Besides, technology progress leads to price reduction thus increased users range and opened broader transmission view for people. On the Micro Age platforms, people can realize some public welfare activities to give play to their values to help the society continue to form a development atmosphere.

Widespread transmission. Under the Micro Age background, people all are information creator and transmitter, the continue increase of micro user cause the wider range of information transmission. And, there are many main platforms of Micro Age information transmission, they are diversified, some users even began to use Internet site, Wechat and other different platforms to publish and read thus to provide benefit channels for Micro Age information.

Transmission mobility. With the utilization of intellectual cellphones, many people began to reduce computer use, because people will not be restricted by space and time by using cellphone, they not only can publish information anytime, also can communicate any time, especially the emerging of on-line shopping, which provided convenience and further realized information mobility.

Transmission timeliness. Traditional medias transfer information through newspaper, broadcasting, TV, but restricted by time and space, which cannot meet people's demand. Nowadays, people begin to use cellphone and computer to publish information timely to realized information timeliness ${ }^{[1]}$.

Information miniature. Content of Micro Age is main miniature, in transmission it only need one sentence or one picture can express its content, which promoted information diversity. Therefore, information in Micro Age not only can help people communicate with leisure time but also can speed up people’s living pace.

Information interaction. The main way for the Micro age emerging is promoting effective information transmission, people can improve their own value through media communication form and form right guidance form to realize rapid social development. Therefore, under the Micro Age development, we should promote people's communication and use basic communication software to promote information transmission to complete information interaction.

Information openness. Under the Micro Age background, no matter different position features, different development regions, people can use Wechat and Microblog to public information and can focus on some positive and negative information.

Receivers' short order. The formation of short order is to inquire information under the condition of not wasting time. Information can be published, received and transferred on different terminals can be finished in a short time. Therefore, in order to improve information transmission efficiency, we should choose attractive information, therefore, a large amount of information is replaced by short order to become the new trend for information transmission.

\section{The influence of Micro Age on English Teaching}

\section{Change of teaching content}

Under the Micro Age background, the change of English teaching content has a big influence. In people's cognition, English teaching content in university mainly includes vocabulary, grammar, communication and writing, and English teaching is mainly in one version. Under the Micro Age background, micro product are transferred fast, not only includes many content, but also improved its transmission ability, thus influenced the back-off phenomenon of English teaching content and real situation in traditional English which reduced students' activity. Face this teaching situation, English teachers should introduce in the application of Wechat and Microblog on the basis of former teaching content, and increase internet vocabulary on these platforms to guarantee English teaching content as well as stimulate students' studying enthusiasm for English knowledge.

\section{Update of teaching form}

Under the Micro Age background, the updating of English teaching form has a huge influence. Because under traditional English teaching forms, it mainly depends on teaching's teaching, 
knowledge received by students is also boring. With the development of micro age, all kinds of advanced technologies are used, such as digital technology, internet technology, information technology and so on, all these provide new development ideas for traditional English teaching ${ }^{[2]}$. Therefore, under this background to implement English teaching,we can use internet form to carry out various teaching activities on campus to meet current teaching demand.

\section{Update of teaching concept}

Under the background of micro age, English teaching concept has been updated greatly, thus produced positive influence. Because traditional English teaching concept is mainly depend on teaching, while under the micro age background, a large amount of information emerging and transmission changed students and teachers' development need and improved students' independent studying ability. Teaching under this form, students are teaching subjects, students not only can search relevant knowledge on the teaching platform but also can combine all disciplinary knowledge for communication and interaction to improve their English application ability. In addition, under this micro age development background, English teaching form also uses scientific technology and advance teaching concept and treat students as teaching subjects to realize different teaching forms.

\section{Challenge faced by English teaching under the Micro Age Background}

\section{Advance teaching technology}

Advance teaching technology puts forward a huge challenge for English teaching under the Micro Age background. Because the Micro Age is based on advance scientific technology, many micro products are developed from advance technology, applying micro product into university English teaching not only promoted information effective transmission, but also realized good interactive teaching to provide more assisting means for English teaching ${ }^{[3]}$. Advance teaching technology also provide university English teaching with great convenience thus to put forward greater challenges for English teachers. Therefore, in university English teaching, we can use all kinds of advance equipment, add a large amount of fresh information into English class, this not only can increase English teachers' knowledge storage but also can meet era change demand.

\section{Open educational concept}

Open educational concept is an important feature of micro age, under this background, students' confidence is strengthened, their independent studying ability is also improved, thus can grasp more English teaching content. Because traditional teaching form has already cannot meet current social demand, in order to realize teaching form in the micro age, teachers should effectively grasp knowledge in advance. But on a certain degree, teachers' role orientation, relationship between teachers and students also faced huge challenge. Therefore, in order to improve English teaching efficiency, teachers should make new orientation for English teaching concept under the current English teaching situation to meet current demand.

\section{English teaching strategy under the Micro Age background}

\section{Application of "micro-class" in university English teaching}

Applying "micro-class" in traditional university English teaching can highlight language environment in university English, can broaden students' cultural view, thus to create a scene class teaching. As a language knowledge, English not only has reasonable teaching regulation but also can take listening, speaking, reading and writing as main teaching content ${ }^{[4]}$. "Micro-class" should stimulate its application form in language teaching, not only need pay attention to language teaching process, but also need integrate teaching concept and ideological form. Take "micro-class" as teaching focus, not only need to realize integration of many factors, but also need innovation, to help 
students integrate in real teaching environment. In addition, teachers also should to know the historical culture and formation reasons for English speaking countries, and can use plenty teaching resources to realize multilevel teaching form, to improve students' language communication capacity.

In order to create scene teaching class, students need to have enough interests for English knowledge and positively take part in studying to broaden their views. Under the current development rend, English has become an international language and is widely used in all kinds of fields, therefore, applying "micro-class" into university traditional English teaching can create scene and narrative class for students thus make students improve their English in real scene. Optimize traditional university English teaching, take "micro-class" as main entry condition, in the long-term teaching field, it not only can improve students' studying ability but also can change dumb English teaching mode.

\section{Exploration of "micro-class" in university English teaching}

In order to realize systematic and serial development of university English teaching under the "micro-class" form, teachers need to explore. "Micro-class" is not just simple combination of micro-video, but also combination of multiple ingredients to complete serial form, among which, teachers should positively integrate students' studying goal, studying situation and studying plan to construct an integration $^{[5]}$. In university English teaching class, teachers should train students in all stages to improve their comprehensive ability. Therefore, teachers should deeply analyze according to different teaching materials and different structural knowledge, and create different teaching scenes, students not only can form all kinds of thinking ways but also can analyze multiple thinking potential. It guide students form independent studying ability under the application of "micro-class" to for a complete class system. Students should control suitable language skill and learn to improve studying quality under "micro-class". The introduction of "micro-class" changed teachers' single method and created a new teaching thus improved students' enthusiasm. This teaching form not just highlight students' subject position, but also promoted the good communication between students and teachers. Therefore, during exploration of "micro-class", teachers should realize systematic teaching form, not only need to increase interaction forms between teachers and students, but also should assign homework for students to help students better grasp knowledge.

In order to realize cohesion and systematic of "micro-class", exploration of "micro-class", China is still in the initial stage, we need continue research and study to construct a comprehensive "micro-class". Therefore, teachers in university should form good communication and cooperation to realize the integrated development of "micro-class" in English teaching thus can realize benefit development goal. Therefore, under this teaching form students not only stimulated their own studying interest, improved independent self-studying ability, but also improved university's English teaching level.

\section{Conclusion}

With the coming of micro age, traditional English teaching method already cannot meet current social development demand. In university English teaching, teachers not only need to change concept, use advance teaching means to improve teaching level, but also need to grasp English teaching under the micro age and to analyze challenges to put forward new solutions.

\section{References}

[1] Dong Yumin. Discussion on the Cognition of University English Teaching Pattern under the Micro Age Background, Journal of Liaoning University of Technology (Social and Scientific Edition),2015(6):121-123. 
[2] Xu Limin. Brief Analysis on the University English Teaching Pattern Reform under the "Micro-class" Background, Young Writers, 2015(33):217-217.

[3] Wang Lina. Discussion on the University English Teaching Reform Based on Micro-class Platform, Journal of Qiqihar Teachers College, 2015(5):144-146.

[4] Zhou Fenfen. Research on the Efficiency of University English Grade Teaching under the Micro Age, Journal of Guangxi College of Education, 2015(5):137-139,161.

[5] Zhang Liang. Discussion on the Application of Micro-class in University English Teaching, File,2016,6(2):619. 